\title{
Clinical Importance of Emerging ESKAPE Pathogens and Antimicrobial Susceptibility Profile from a Tertiary Care Centre
}

\author{
Jagadevi, B. Saipriya*, D.S. Shubha, K.S. Sudhindra, A. Sumantha and K.R. Madhuri \\ Department of Microbiology, Basaveshwara Medical College and Hospital, \\ Chitradurga, Karnataka, India \\ *Corresponding author
}

\begin{tabular}{|l|}
\hline Ke y w o r d s \\
$\begin{array}{l}\text { Antimicrobial resistance, } \\
\text { ESKAPE pathogens, } \\
\text { Multidrug resistant } \\
\text { (MDR) bacteria }\end{array}$ \\
\hline Article Info \\
\hline $\begin{array}{l}\text { Accepted: } \\
\text { 20 April } 2018 \\
\text { Available Online: } \\
\text { 10 May } 2018\end{array}$ \\
\hline
\end{tabular}

\section{A B S T R A C T}

Bacterial species from the ESKAPE group (Enterococcus faecium, Staphylococcus aureus, Klebsiella pneumoniae, Acinetobacter baumannii, Pseudomonas aeruginosa and Enterobacter species) have high resistance rates by escaping the action of the antimicrobials and are responsible for two third of all health care associated infections. Aim of our study was to find out the bacterial profile and characterize the antimicrobial resistance in ESKAPE pathogens isolated from various specimens. A three year retrospective study was undertaken. Urine samples, pus/wound swabs, respiratory samples, blood samples received in the microbiology laboratory were included \&processed as per standard techniques and bacteria identified. Antibiotic susceptibility was determined according to Clinical \& Laboratory Standards Institute (CLSI) guidelines. $41.5 \%$ of S. aureus isolates were confirmed to be methicillin resistant and 5.9\% vancomycin resistant enterococci (VRE) were identified. A high multidrug resistance was observed for Acinetobacter and $P$. aeruginosa than Enterobacteriaceae. For carbapenem group, resistance varied from 8 to $27 \%$. Resistance to amikacin and netilmycin was lower (4$11 \%$ ) for gram negative ESKAPE pathogens. Antimicrobial resistance surveillance reports on regular basis can provide valuable insight into resistance trends at a particular medical facility to assist in guidance in the appropriate choice of empiric therapy in diseases due to ESKAPE pathogens.

\section{Introduction}

Antimicrobial resistance has been on the rise in the past few years in all parts of the world and has become a challenge to health care system. Although the overall global mortality has decreased in the last three decades due to infections, it is still the most important cause of disability (Lozano et al., 2010; Murray, 2010) and India is no exception which shows the same trends. Antimicrobial resistance is particularly worrying in India, where hospital standards are inconsistent and antibiotics are readily available over the counter at pharmacies. Antibiotic use is unnecessary or inappropriate in as many as $50 \%$ of cases and this creates unnecessary pressure for the selection of resistant species (John et al., 2011).

Infectious Diseases Society of America (IDSA), has highlighted a group of antibiotic 
resistant bacteria as "ESKAPE pathogens", because they effectively escape the effects of antibacterial drugs (Jack N. Pendleton et al., 2013). ESKAPE is an acronym for the group of bacteria, encompassing both Gram-positive and Gram-negative species, made up of Enterococcus faecium, Staphylococcus aureus, Klebsiella pneumoniae, Acinetobacter baumannii, Pseudomonas aeruginosa, and Enterobacter species.

ESKAPE bacteria are common causes of severe and often deadly infections such as bloodstream infections, pneumonia and urinary tract infections. They can cause serious life threatening infections amongst critically ill and immunocompromised individuals and their clinical importance relies on their virulence, ability in developing mechanisms to decrease susceptibility to antimicrobials, increasing inappropriate therapy and affecting negatively on ICU patients' outcome (Sandiumenge et al., 2012).

The incidence of ESKAPE pathogens as etiologic agents of human disease has increased with time, and infections resulting from antimicrobial-resistant ESKAPE pathogens have been observed to be associated with poorer patient outcomes than infections arising from similar antimicrobial-susceptible isolates (Pogue Jmkaye et al., 2015; James A. Karlowsky et al., 2017). Importantly, patients infected with antimicrobial-resistant ESKAPE pathogens more frequently receive inappropriate empirical antimicrobial therapy than do patients with antimicrobial-susceptible pathogens leading to higher case fatality rates and opportunities for spread to neighbouring patients (Bodro et al., 2013, James A. Karlowsky et al., 2017).

Emergence of multidrug resistant organisms leading to treatment failure is of concern. It is necessary that studies trace periodically the bacterial resistance profile, to contribute for both local and global epidemiological data. These data assist in therapeutic management, since they consider the prevalence of resistance locally, adding it to the clinical effectiveness and cost of the antimicrobial. The aim of the current study is to satisfy this need by reporting the bacterial profile and antimicrobial susceptibility pattern of culture positive ESKAPE pathogens isolated in various clinical specimens.

\section{Materials and Methods}

A three year retrospective study from September 2013 to August 2016was carried out in a tertiary care Centre at Basaveshwara medical college and hospital, Chitradurga. During this period, urine samples (3989), pus/wound samples (2293), respiratory samples (2397) and blood samples (1434) received at our microbiology laboratory were included in the study.

All the above samples were processed as per standard microbiological techniques and isolates identified based upon gram staining characteristics, colony morphology, motility, oxidase test, catalase test and a panel of standard biochemical tests.

Following identification of the bacterial isolates, antibiotic susceptibility testing was performed on Mueller- Hinton agar plates by Kirby- Bauer disk diffusion method as per Clinical and Laboratory Standard Institute guidelines (CLSI 2013). The antibiotics tested included beta-lactam group (penicillins and cephalosporins), aminoglycosides, macrolides, clindamycin, glycopeptides, colistin, carbapenem, fluoroquinolones, cotrimoxazole and nitrofurantoin. However, some modification was done based on the organism. For example, for gram negatives, glycopeptides like vancomycin (which are specific for gram positives) were not tested. 
The antibiotics discs and their concentrations for gram positive bacteria included; Ampicillin $(10 \mu \mathrm{g})$, Cotrimoxazole (1.25/23.75 $\mu \mathrm{g})$, Ciprofloxacin $(5 \mu \mathrm{g})$, Gentamicin $(10 \mu \mathrm{g})$, High level Gentamicin (120 $\mu \mathrm{g})$, Erythromycin $(15 \mu \mathrm{g})$, Clindamycin $(2 \mu \mathrm{g})$, Clarithromycin $(15 \mu \mathrm{g})$, Cefoxitin $(30 \mu \mathrm{g})$, Tetracycline $(30 \mu \mathrm{g})$, Amoxycillin/Clavulanic acid $(20 / 10 \mu \mathrm{g})$, Vancomycin $(30 \mu \mathrm{g})$ and

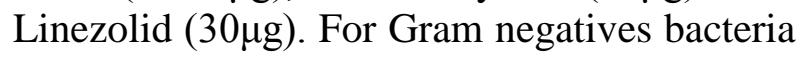
included; Ampicillin $(10 \mu \mathrm{g})$, Cotrimoxazole $(1.25 / 23.75 \mu \mathrm{g})$, Gentamicin $(10 \mu \mathrm{g})$, Amikacin $(30 \mu \mathrm{g})$, Netilmycin (30 $\mu \mathrm{g})$, Ciprofloxacin $(5 \mu \mathrm{g}), \quad$ Levofloxacin $(5 \mu \mathrm{g})$, Nitrofurantoin $(300 \mu \mathrm{g}), \quad$ Cefepime $(30 \mu \mathrm{g})$, Ceftriaxone $(30 \mu \mathrm{g})$, Ceftazidime $(30 \mu \mathrm{g})$, Cefaperazone - Sulbactum (75 $\mu \mathrm{g})$, Piperacillin - Tazobactum (100/10 $\mu \mathrm{g})$, Imipenem $(10 \mu \mathrm{g})$, Meropenem $(10 \mu \mathrm{g})$, Amoxycillin/Clavulanic $\operatorname{acid}(20 / 10 \mu \mathrm{g})$, Aztreonam $(30 \mu \mathrm{g})$, Colistin $(10 \mu \mathrm{g})$ discs were used. All the antimicrobials used for the study were obtained from Himedia, India. The reference strains used as control were E. coli (ATCC 25922) and S. aureus (ATCC 25923). In this study multi-drug resistance was defined as simultaneous resistance to two or more antimicrobial agents.

Detection of MRSA: Methicillin resistance was detected by Cefoxitin disk diffusion test. Lawn culture was done onto Mueller-Hinton agar plate. A $30 \mu \mathrm{g}$ cefoxitin disc was placed and incubated at $3^{\circ} \mathrm{C}$ for $24 \mathrm{hrs}$. The zone of inhibition of $S$. aureus $\leq 21 \mathrm{~mm}$ were considered as methicillin resistant.

\section{Results and Discussion}

During the study period a total of 10, 113 various clinical samples were examined, $29.64 \%(2998 / 10,113)$ were culture positive. Of this culture positive samples, maximum growth was seen from pus/wound swabs, $42.25 \%(985 / 2293)$ followed by $30.99 \%$ (743/2397) respiratory samples, $28.95 \%$
(1156/3989) from urine samples and 7.94\%(114/1434) from blood samples. Overall growth of Gram negative bacilli (GNB) were $69.44 \%$ (2082/2998) and Gram positive cocci (GPC) were 29.35 \% (880/2998). These findings are consistent with Anuradha S De et al., 2017; Daniely M. Silva et al., (2017). The global scenario shows that Gram- positive infections are more prevalent in the Western world, however, Gram- negative bacterial infections dominate in India and Asia- Pacific region (DhruvaChaudhry et al., 2016).

In this study, it is seen that, of the total 2998 positive cultures (Table 1), 2, 107(70.28\%) were ESKAPE pathogens and 891(29.72\%) were non ESKAPE pathogens. Among the ESKAPE pathogens, the most prevalent microorganism isolated was Staphylococcus aureus $19.17 \%$ (575), followed by Klebsiella pneumoniae $16.14 \%$ (484), Pseudomonas aeruginosa $10.97 \%$ (329), Acinetobacter species 9.67\%(290), Enterococcus species $7.30 \%$ (219) and Enterobacter species $7.00 \%$ (210). Our study results correlated with other workers Anuradha S. De et al., (2017), Jorge Martín L. laca-Díaz et al., (2017), Dhruva Chaudhry et al., (2016). A study from Brazil by Daniely M. Silva et al., (2012), also reported similar isolation rate of ESKAPE pathogens, they documented the Klebsiella pneumoniae $(41 \%)$ as most prevalent microorganism followed by Staphylococcus aureus (22\%), Pseudomonas aeruginosa (14\%), Enterobacter spp. (11\%), Acinetobacter baumannii (8\%) and Enterococcus faecium (4\%).

Among non ESKAPE pathogens Escherichia coli was the most predominant microorganism isolated in $19.31 \%$ (579 samples), followed by NFGNB 4.46\% (134), Coagulase Negative Staphylococcus (CONS) $1.90 \% \quad$ (57), Citrobacter species $1.06 \%$ (32), Streptococcus species $0.96 \%$ (29), Proteus species 0.70\% (21), Salmonella typhi $0.10 \%$ (3) and Candida 
albicans $1.20 \% \quad$ (36). Our study results correlated with other workers (Razia Khatoon et al., 2016; Rudrajit Paul et al., 2017; Sugantha Valli et al., 2017).

Majority of isolates from urine and respiratory samples were gram negative bacilli, $81.92 \%$ (947/1156) and 82.23\% (565/743) respectively while from pus/wound swabs and blood cultures the majority of isolates were gram positive cocci $50.4 \%(497 / 985)$ and $57.8 \%$ (66/114) respectively. In urine and respiratory samples the microorganism most commonly isolated was Klebsiella pneumoniae $49.17 \%$ (238/484) and $42.35 \%$ (205/484) respectively and in pus/wound swab and blood cultures, Staphylococcus aureus was the most commonly isolated microorganism $72.17 \%$ $(415 / 575)$ and $8 \%(46 / 575)$ respectively. Our study results correlated with Daniely M. Silva et al., (2017), Anuradha De et al., (2015). The main problem across most sites of infections as shown above is Gram Negative bacillary infections. This is the scenario in most centers in India. This is quite different from the Western setting where the major share of hospital associated infections since the 1980's are Gram positive coccal organisms like Staphylococcus aureus and Enterococci. (George K. Varghese et al., 2010; Gaynes et al., 2005).

\section{Antimicrobial susceptibility in ESKAPE pathogens}

Enterococci were traditionally regarded as low-grade pathogens, but have emerged as an increasingly important cause of health care infections in recent years (Sood et al., 2006). Vancomycin resistant Enterococci (VRE) has been increasingly reported from all parts of the world. In present study 5.93\% (13/219) isolates were resistant to vancomycin. $1.4-8$ $\%$ resistance to vancomycin has been reported in India by Kapoor et al., (2005), Shah et al., (2012), Taneja et al., (2004), Karmarkar et al.,
(2004) in separate studies, but Preeti Srivastava et al., (2013) reported a prevalence of $27 \%$ VRE.

In the present study, Enterococci showed highest resistance to ampicillin(98.6\%), followed by erythromycin (62.7\%), ciprofloxacin (56.3\%), Tetracycline $(54.6 \%)$, clindamycin $(51.6 \%)$, nitrofurantoin $(29.7 \%)$ and linezolid showed lowest resistance $(0 \%)$, these findings are consistent with studies done by Preeti Srivastava et al., (2013), Kapoor et al., (2005). 21.4\% High level Gentamicin resistance (HLAR) of Eneterococci was detected in our study, similar resistance rate was reported by Anuradha S. De et al., (2015). More than $50 \%$ resistance with gentamicin was reported by Butch et al., (2011) and Nepal et al., (2013).

Among Gram-positive pathogens of ESKAPE group, the majority were $S$. aureus strains (19.1\%). The following resistance rates of $S$. aureus were identified in the descending order to: ampicillin (97.2\%), cotrimoxazole (78.2\%), tetracycline $(71.4 \%)$ gentamicin (66.2\%), erythromycin (59.6\%), ciprofloxacine (51.8\%), levofloxacine $(46.7 \%)$, and amoxicillin-clavulanate $(36.4 \%)$. Inducible clindamycin resistance was $(42.8 \%)$. These finding correlated with Sangeeta Joshi et al., (2013) and Sathish et al., (2017). S. aureus isolates exhibited $100 \%$ sensitivity with vancomycin and linezolid which is similar to study done by Abbas et al., (2015).

Reports of methicillin-resistant Staphylococcus aureus (MRSA)emerged in the 1960s, and currently, MRSA isolates are estimated to account for $25 \%$ of $S$. aureus isolates, with a prevalence of up to $50 \%$ or more in some areas (Sirijan Santajit et al., 2016). In our study, prevalence of MRSA was $41.5 \%$ which correlated with studies done by Sangeeta Joshi et al., (2013) who reported $42 \%$ MRSA. In India, the incidence of MRSA 
is increasing, with prevalence rates varying from $23.6 \%$ to as high as $59.3 \%$ (Tiwari et al., 2006; Boucher et al., 2009; Lockhart et al., 2007).

In recent years, many $K$. pneumoniae strains have acquired a massive variety of $\beta$ lactamase enzymes, which can destroy the chemical structure of $\beta$-lactam antibiotics such as penicillins, cephalosporins and carbapenems (SirijanSantajit et al., 2016). Because carbapenems are conventionally used to treat persistent infections caused by Gramnegative bacteria, the increasing prevalence of carbapenem-resistant $K$. pneumoniae (CRKP), with resistance encoded by blaKPC, presents a significant challenge for physicians (Queenan et al., 2007; Bush et al., 1995). In addition, the emergence of the $K$. pneumoniae super enzyme, known as NDM-1 and encoded by blaNDM-1, has increased the proportion of carbapenem-resistant $K$. pneumoniae isolates and may pose a threat to other antibiotics such as $\beta$-lactams, aminoglycosides, and fluoroquinolones (Kumarasamy et al., 2010; Yong et al., 2009).

When analyzing the susceptibility profile for Klebsiella pneumoniae, in our study it was possible to observe that this strain presented the highest resistance rates to the following antimicrobials: to Ampicillin (100\%), Trimethoprim-sulphamethoxazole (89.4\%), Ciprofloxacine $(87.3 \%)$ levofloxacin $(86.9 \%)$, nitrofurantoin $\quad(79.8 \%)$ amoxycillinclavulanate $(72.5 \%)$, aztreonam $(49.2 \%)$ and the lowest rate of resistance to colistin $(1 \%)$, imipenem (18.4\%), meropenem (15.6\%), amikacin $(4.1 \%)$, netilmycin $(3.8 \%)$ these findings correlated with the other workers (Daniely M. Silva et al., 2017; Anuradha S. De et al., 2015).

Table.1 Showing ESKAPE bacteria and Non- ESKAPE bacteria isolated from different samples

\begin{tabular}{|c|c|c|c|c|}
\hline Bacteria (Total no.) & Pus No (\%) & $\begin{array}{l}\text { Respiratory No } \\
(\%)\end{array}$ & Urine No (\%) & Blood No (\%) \\
\hline \multicolumn{5}{|l|}{ ESKAPE bacteria $(2,107)$} \\
\hline Enterococcus species (219) & $55(25.11)$ & $67(30.59)$ & $83(37.89)$ & $14((6.39)$ \\
\hline $\begin{array}{l}\text { Methicillin sensitive Staphylococcus } \\
\text { aureus (MSSA) (336) }\end{array}$ & $237(70.53)$ & $35(10.41)$ & $37((11.01)$ & $27(8.03)$ \\
\hline $\begin{array}{l}\text { Methicillin Resistance Staphylococcus } \\
\text { aureus (MRSA) (239) }\end{array}$ & $178(74.47)$ & $18(7.53)$ & $24(10.04)$ & 19(7.94) \\
\hline Klebsiella pneumoniae (484) & $36(7.43)$ & $205(42.35)$ & $238(49.17)$ & $05(1.03)$ \\
\hline Acinetobacter species (290) & $97(33.48)$ & $113(38.96)$ & $67(23.10)$ & $13(4.48)$ \\
\hline Pseudomonas aeruginosa (329) & $153(46.50)$ & 97(29.48) & $73(22.18)$ & $06(1.82)$ \\
\hline Enterobacter species (210) & $72(34.28)$ & $47(22.38)$ & $82(39.04)$ & $09(4.28)$ \\
\hline \multicolumn{5}{|l|}{ Non- ESKAPE bacteria (891) } \\
\hline Escherichia coli (579) & $80(13.18)$ & $76(13.12)$ & $419(72.36)$ & $04(0.69)$ \\
\hline Citrobacter species(32) & $09(28.12)$ & 07(21.87) & $14(43.75)$ & $02(6.25)$ \\
\hline Proteus (21) & 07(33.33) & 04(19.04) & 08(38.09) & $02(9.51)$ \\
\hline NFGNB (134) & $31(23.14)$ & $53(39.55)$ & $46(34.32)$ & $04(2.98)$ \\
\hline Salmonella typhi (03) & 00 & 00 & 00 & 03(100) \\
\hline CONS (57) & $13(22.80)$ & 00 & $39(68.42)$ & $05(8.77)$ \\
\hline Streptococcus species(29) & 14(48.27) & O9(31.03) & $05(17.24)$ & $01(3.44)$ \\
\hline Candida albicans (36) & 03(8.33) & 12(33.33) & $21(58.33)$ & 00 \\
\hline
\end{tabular}


Table.2 Antimicrobial resistance pattern of culture positive ESKAPE bacteria

\begin{tabular}{|c|c|c|c|c|c|c|}
\hline \multirow{2}{*}{$\begin{array}{l}\text { Antimicrobial } \\
\text { drugs }\end{array}$} & \multicolumn{6}{|c|}{ Resistant Pattern of bacterial isolates (\%) } \\
\hline & $\begin{array}{l}\text { Enterococci } \\
\text { spp, } \mathrm{N}=219\end{array}$ & $\begin{array}{l}\text { S. aureus } \\
\mathrm{N}=575\end{array}$ & $\begin{array}{l}\text { K. pneumoniae } \\
\mathrm{N}=484\end{array}$ & $\begin{array}{l}\text { Acinetobacter } \\
\text { spp, } N=290\end{array}$ & $\begin{array}{l}P . \text { aeruginosa } \\
\mathrm{N}=329\end{array}$ & $\begin{array}{l}\text { Enterobacter } \\
\text { Spp, } \mathrm{N}=210\end{array}$ \\
\hline Ampicillin & $98.6 \%$ & $97.2 \%$ & $100 \%$ & - & - & $100 \%$ \\
\hline Cotrimoxazole & - & $78.3 \%$ & $89.4 \%$ & $72.6 \%$ & $76.2 \%$ & $88.4 \%$ \\
\hline Ciprofloxacin & $56.3 \%$ & $51.8 \%$ & $87.3 \%$ & $90.5 \%$ & $86.8 \%$ & $83.1 \%$ \\
\hline Levofloxacin & $49.1 \%$ & $46.7 \%$ & $86.9 \%$ & $89.2 \%$ & $85.7 \%$ & $82.8 \%$ \\
\hline Gentamicin & - & $66.2 \%$ & $69.7 \%$ & $53.6 \%$ & $49.3 \%$ & $65.6 \%$ \\
\hline $\begin{array}{l}\text { High level } \\
\text { Gentamicin }\end{array}$ & $21.4 \%$ & - & - & - & - & - \\
\hline Clarithromycin & $60.6 \%$ & $58.3 \%$ & - & - & - & - \\
\hline Erythromycin & $62.7 \%$ & $59.6 \%$ & - & - & - & - \\
\hline Clindamycin & $51.6 \%$ & $42.8 \%$ & - & - & - & - \\
\hline Cefoxitin & - & $41.5 \%$ & - & - & - & - \\
\hline Tetracycline & $54.6 \%$ & $71.3 \%$ & - & - & - & - \\
\hline Vancomycin & $5.93 \%$ & $0 \%$ & - & - & - & - \\
\hline Linezolid & $0 \%$ & $0 \%$ & - & - & - & - \\
\hline $\begin{array}{l}\text { Amoxycillin/Clavul } \\
\text { anic acid }\end{array}$ & - & $36.4 \%$ & $72.5 \%$ & $78.4 \%$ & $76.2 \%$ & $74.9 \%$ \\
\hline Nitrofurantoin & $29.7 \%$ & $50.9 \%$ & $79.8 \%$ & $81.2 \%$ & $80.6 \%$ & $76.3 \%$ \\
\hline Amikacin & - & - & $4.1 \%$ & $10.7 \%$ & $9.3 \%$ & $8.6 \%$ \\
\hline Netilmycin & - & - & $3.8 \%$ & $9.2 \%$ & $8.6 \%$ & $5.4 \%$ \\
\hline Ceftriaxone & - & - & $80.4 \%$ & $87.3 \%$ & $78.4 \%$ & $81.9 \%$ \\
\hline Cefepime & - & - & $71.5 \%$ & $84.6 \%$ & $76.2 \%$ & $70.2 . \%$ \\
\hline Ceftazidime & - & - & $62.7 \%$ & $87.3 \%$ & $79.6 \%$ & $69.6 \%$ \\
\hline $\begin{array}{l}\text { Cefaoperazone- } \\
\text { Sulbactum }\end{array}$ & - & - & $61.3 \%$ & $19.6 \%$ & $16.8 \%$ & $65.3 \%$ \\
\hline $\begin{array}{l}\text { Piperacillin - } \\
\text { Tazobactum } \\
\end{array}$ & - & - & $78.6 \%$ & $62.9 \%$ & $61.4 \%$ & $79.2 \%$ \\
\hline Imipenem & - & - & $18.4 \%$ & $27.2 \%$ & $10.4 \%$ & $16.7 \%$ \\
\hline Meropenem & - & - & $15.6 \%$ & $21.7 \%$ & $8.2 \%$ & $14.3 \%$ \\
\hline Aztreonam & - & - & $49.2 \%$ & $46.2 \%$ & $49.6 \%$ & $39.5 \%$ \\
\hline Colistin & & & $1.0 \%$ & $2.5 \%$ & $1.0 \%$ & $1.5 \%$ \\
\hline
\end{tabular}

Table.3 Multidrug resistant (MDR) Gram negative bacilli isolated between 2013 and 2016

\begin{tabular}{|l|l|l|}
\hline Year & Gram negative bacilli (No) & Total MDR No. (\%) \\
\hline $\mathbf{2 0 1 3 - 2 0 1 4}$ & Enterobacteriaceae (427) & $113(26.4 \%)$ \\
\hline & Non-fermenters (304) & $179(58.8 \%)$ \\
\cline { 2 - 3 } & Total (731) & $292(39.9 \%)$ \\
\hline \multirow{2}{*}{$014-2015$} & Enterobacteriaceae (504) & $172(34.1 \%)$ \\
\cline { 2 - 3 } & Non-fermenters (198) & $91(47.3 \%)$ \\
\cline { 2 - 3 } & Total (702) & $263(37.4 \%)$ \\
\hline \multirow{2}{2015-2016}{} & Enterobacteriaceae (397) & $117(29.4 \%)$ \\
& Non-fermenters (252) & $136(53.9 \%)$ \\
& Total (649) & $253(38.92 \%)$ \\
\hline
\end{tabular}


Rates of susceptibility of Klebsiella pneumoniae, for cephalosporinsin our study were Ceftriaxone (80.4\%), Ceftazidime (62.5\%) cefoperazone -sulbactam (61.3\%), cefepime (71.5\%). Karlowsky et al., (2017), Daniely M. Silva et al., (2017) and Rudrajit Paul et al., (2017) also reported similar rate of resistance.

Recently, the emergence of carbapenemase producing $A$. baumannii strains carrying imipenem metallo $\beta$-lactamases, encoded by blaIMP, and oxacillinase serine $\beta$ lactamases, encoded by blaOXA, has been reported. These strains show resistance to both colistin and imipenem, and the combination of resistance genes makes them capable of evading the action of most traditional antibiotic compounds (Vila et al., 2007; Bradley et al., 2009).

In the present study Acinetobacter baumannii presented the most worrying susceptibility profile, presenting a higher resistance frequency of $90.5 \%$ to ciprofloxacin, $89.2 \%$ to levofloxacin, $87.3 \%$ to ceftazidime and cefotaxime, $84.8 \%$ to cefepime, $87.3 \%$ to piperacillin tazobactam and Lower resistance frequency to colistin (2.5\%) amikacin $(10.7 \%)$, netilmycin $(9.2 \%)$, cefoperazonesulbactam (19.6\%), meropenem (21.7\%)and imipenem (27.2\%). These frequencies of resistance to Acinetobacter correlated with other workers (Daniely M. Silva et al., 2017; Anuradha S De et al., 2015; Rudrajit Paul et al., 2017) (Table 2).

Many $P$. aeruginosa strains show an intrinsic reduced susceptibility to several antibacterial agents, as well as a propensity to develop resistance during therapy especially in carbapenem-resistant (chiefly imipenem) strains. The combination of these leads to high rates of carbapenem resistance amongst P. aeruginosa isolates and also to the emergence of fluoroquinolone-resistant strains as the corresponding mechanisms of resistance may be carried by the same plasmid (Livermore et al., 2002; Bush et al., 1998).

In our study $P$. aeruginosa was found highly resistant to ciprofloxacin (86.8\%), levofloxacin (85.7\%), ceftazidime (79.6\%), cefepime $(76.2 \%)$, Amoxycilline-clavulanate $(76.2 \%)$ and piperacillin-tazobactam $(61.4 \%)$ and lower resistance to colistin (1\%) amikacin (9.3\%), netilmycin (8.6\%), imipenem $(10.4 \%)$ and meropenem (8.2\%). Daniely M. Silva et al., (2017), Anuradha S De et al., (2015), Jorge Martín L laca-Díaz et al., (2012), Rudrajit Paul et al., (2017) also reported similar rate of resistance.

As observed for $K$. pneumoniae, in general, Enterobacter spp. were less susceptible to the antimicrobials tested. Enterobacter spp., showed higher rate resistance to ampicillin $(100 \%)$, ciprofloxacin $(81.3 \%)$, levofloxacin $(82.8 \%)$, ceftriaxone $(81.9 \%)$, piperacillintazobactam (79.2\%), cefepime $(70.2 \%)$ and lower resistance to amikacin (8.6\%), netilmycin (5.4\%), imipenem (16.7\%), meropenem (14.3). Similar resistance rate was reported by Anuradha S. De et al., (2015), Daniely M. Silva et al., (2017), Jorge Martín L laca-Díaz et al., (2012) and Rudrajit Paul et al., (2017).

Overall multidrug resistant gram negative bacilli (MDR-GNB) isolated in our study in three years 2013-2014, 2014-2015 and 20152016 was $39.9 \%, 37.4 \%$ and $38.9 \%$ respectively. In general, a high MDR was observed for A. baumannii and P. aeruginosa (Non-fermenting bacilli) than Enterobacteriaceae (Table 3). $\quad 81.7 \%$ (237/290) of $A$. baumannii isolates were MDR, as were $85.9 \% \quad(98 / 210)$ of Enterobacter spp., $65.2 \%$ (316/484) of $K$. pneumoniae and 59.8\% (197/329) of $P$. aeruginosa. E. coli deserves special attention because it also showed a high level of MDR 
$62.8 \%(364 / 579)$, even though this bacterial species is not included within the ESKAPE group. Jorge Martín L. laca-Díaz et al., (2012) and Anuradha S De et al., (2015) also reported similar rate of MDR-GNB.

Both infection and MDR results in a considerable clinical and economic burden and the presence of MDR boosts the deleterious impact of health care associated infection (Salgado et al., 2005). Compared with infections not caused by MDR microorganisms, the additional cost of multidrug resistance in hospitalized patients with infections has been estimated to be much higher per patient (Cosgrove, 2006; DhruvaChaudhry et al., 2016). The continuous increase of MDR isolates presents a complicated situation for antimicrobial therapy; however, colistinis still effective in most cases (Boucher et al., 2009).

Present study indicates a serious problem in the treatment of infections and current resistance pattern emphasizes the importance of strict antibiotic policy to prevent emergence and spread of antibiotic resistance. In this tertiary care hospital, the ESKAPE pathogens were responsible for a considerable number of infections and represented the majority of isolates for which resistance to multiple antimicrobial agents reduces therapeutic alternatives for physicians. The awareness of residential antimicrobial resistance pattern can support the selection of convenient empirical treatment in which infections occur due to ESKAPE pathogens.

In view of high drug resistance, caution should be exercised and wide spread use of antibiotics should be avoided to minimize the potential development of multidrug and sometimes pan drug resistant pathogens. Every health- care institution must develop its own antimicrobial stewardship program which should be based on the local epidemiological data and standard guidelines, to optimize the antimicrobial use among the hospitalized patients, to improve the patient outcomes, to ensure a cost- effective therapy, to reduce the adverse consequences of the antimicrobial use and to limit the emergence and transmission of drug resistant bacteria. Preventive measures such as a continuous surveillance of the health care centers and treatment based on antibiogram and a strict implementation of infection control practices are essential in containing the threat of drug resistance in the health- care settings.

\section{References}

Abbas A, Nirwan PS, Srivastava P. 2015. Prevalence and antibiogram of hospital acquired-methicillin resistant Staphylococcus aureus and community acquired-methicillin resistant Staphylococcus aureus at a tertiary carehospital National Institute of Medical Sciences. Community Acquir Infect, 2:13- 5.

Adriana Slavcovici, Codrutamaier, Amanda Radulescu.2015.Antimicrobial resistance of eskape-pathogens in culture-positive pneumonia.Farmacia, vol. 63, 2.201- 205.

Anuradha S de, Baveja S, D'Souza D and Patwegar S.2015. Antimicrobial resistance among commonly encountered bacteria isolated in 2013The ESKAPE Menace. Intern Med. volume 5. Issue 3. http://dx.doi.org/ 10.4127/2165-8048.1000193

Bodro M, Sabe N, Tubau F, Lladó L, Baliellas C et al.,. 2013.Risk factors and outcomes of bacteremia caused by drugresistant ESKAPE pathogens in solidorgan transplant recipients. Transplantation 2013; 96:843-849.

Boucher HW, Talbot GH, Bradley JS, Edwards JE, Gilbert D, et al., 2009. Bad bugs, no drugs: no ESKAPE! An update 
from the Infectious Diseases Society of America.Clin Infect Dis 48: 1-12.

Bush, K., G. A. Jacoby, and A. A. Medeiros. 1995. "A functional classification scheme for $\beta$-lactamases and its correlation with molecular structure," Antimicrobial Agents and Chemotherapy, vol. 39, no. 6, pp. 12111233.

Butcu M, Akcay SS, Inan AS, Aksaray S, Engin S, and Calisici G. 2011. In vitro susceptibility of enterococci strains isolated from urine samples. J Infect chemother.17(4): 575-8.

Chaudhry D, Prajapat B. Intensive care unit bugs in India. 2017. How do they differ from the Western world? J Assoc Chest Physicians;5:10-7

Cosgrove SE. 2006. The relationship between antimicrobial resistance and patient outcomes: Mortality, length of hospital stay, and health care costs. Clin Infect Dis. 42 Suppl 2:S82- 9.

Daniely M. Silva, Eulina Maria N. Menezes, Emerson V. Silva; Thaís A. C. Lamounier.2017.Prevalence and antimicrobial susceptibility profile of ESKAPE pathogens from the Federal District, Brazil. J Bras Patol Med Lab, v. 53 , n. 4, p. 240-245

Dr Razia Khatoon, Mahak Jain, Dr Noor Jahan, Mukesh Kumar Singh, ShivendraDutt, MohdShahid Khan. 2016: Evaluation of antimicrobial sensitivity and resistance pattern of Gram positive and Gram negative bacteria to monitor drug resistance among clinical isolates. Indian Journal of Basic and Applied Medical Research; Vol.-5, Issue- 3, P. 72-82

George K Varghese1, Chiranjay Mukhopadhya2, Indira Bairy2, KE Vandana2, Muralidhar Varma.2010. Bacterial Organisms and Antimicrobial Resistance Patterns. supplement to JAPI, vol. 58
Jack N Pendleton, Sean P Gorman, Brendan F Gilmore. 2013.Expert Rev Anti Infect Ther.11(3).297-308.

James A. Karlowsky, Daryl J. Hoban, Meredith A. Hackel, Sibylle H. Lob, and Daniel F. Sahm.2017. Antimicrobial susceptibility of Gramnegative ESKAPE pathogens isolated from hospitalized patients with intraabdominal and urinary tract infections in Asia-Pacific countries: SMART 2013-2015. Journal of Medical Microbiology.66:61-69.

John TJ, Dandona L, Sharma VP, Kakkar M. 2011.Continuing challenge of infectious diseases in India. Lancet 2011;377:252- 69.

Jorge Martín L laca-Díaz, Soraya MendozaOlazarán, Adrian Camacho-Ortiz, Samantha Flores, Elvira GarzaGonzález.2012. One-Year Surveillance of ESKAPE Pathogens in an Intensive Care Unit of Monterrey, Mexico. Chemotherapy 58:475-481. D OI: 10.1159/000346352

KalpeshGohel, AmitJojera, ShaileshSoni, SishirGang, RavindraSabnis, andMaheshDesai. 2014. Bacteriological Profile and Drug Resistance Patterns of Blood Culture Isolates in a Tertiary Care Nephrourology Teaching Institute. BioMed Research International. Article ID 153747, 5 pages.

Kapoor L, Randhawa VS, Deb M. 2005. Antimicrobial resistance of enterococcal bold isolates at a pediatric care hospital in India. Jpn Infect Dis58:101-103.

KarmarkarMG, GershomES, Mehta PR.2004.Enterococcal infection with special reference to phenotypic characterization \& drug resistance. Indian J Med Res 119Suppl:22-25.

Kumarasamy, K.K., M. A. Toleman, T. R. Walsh et al., 2010. "Emergence of a new antibiotic resistance mechanism in India, Pakistan, and the UK: a 
molecular, biological, and epidemiological study," The Lancet Infectious Diseases, vol.10, no.9, pp.597-602.

Livermore, D.M., 2002. "Multiple mechanisms of antimicrobial resistance in Pseudomonas aeruginosa: our worst nightmare?" Clinical Infectious Diseases, vol. 34, no.5, pp.634-640.

Lockhart SR, Abramson MA, Beekmann SE, Gallagher G, Riedel S, et al., 2007. Antimicrobial resistance among Gramnegative bacilli causing infections in intensive care unit patients in the United States between 1993 and 2004. J Clin Microbiol 45: 3352-3359.

Lozano R, Naghavi M, Foreman K, Lim S, Shibuya K, Aboyans V, et al., Global and regional mortality from 235 causes of death for 20 age groups in 1990 and 2010: A systematic analysis for the Global Burden of Disease Study 2010. Lancet 2012; 380: 2095- 128.

Murray CJ, Vos T, Lozano R, Naghavi M, Flaxman AD, Michaud C, et al., 2012. Disability- adjusted life years (DALYs) for 291 diseases and injuries in 21 regions, 1990- 2010: A systematic analysis for the Global Burden of Disease Study 2010. Lancet; 380: 2197- 223.

Nepal HP, Khanal B and Acharya A. 2013. Charecterization and antimicrobial resistance of clinical isolates of Enterococci in tertiary care hospital in eastern Nepal. Health Renaissance. 11(1): 17-22.

Pogue JM, Kaye KS, Cohen DA, Marchaim D. 2015. Appropriate antimicrobial therapy in the era of multidrug-resistant human pathogens. Clin Microbiol Infect. Apr; 21(4): 302-12.

Preeti Srivastava, Raman Mehta, PS Nirwan, Meeta Sharma, SS Dahiya.2013. Prevalence and antimicrobial susceptibility of Enterococcus species isolated from different clinical samples in a tertiary care hospital of north India. National journal of medical research. Volume 3.Issue 4

Queenan, A.M., and K. Bush.2007. "Carbapenemases: the versatile $\beta$ lactamases," Clinical Microbiology Reviews, vol. 20, no. 3, pp. 440-458.

Rudrajit Paul, Jayanti Ray, SouravSinha, Jayati Monda.2017. Antibiotic resistance pattern of bacteria isolated from various clinical specimens: an eastern Indian study. Int J Community Med Public Health.Apr;4(4):1367-1371

Salgado CD, O'Grady N, Farr BM. 2005.Prevention and control of antimicrobial- resistant infections in intensive care patients. Crit Care Med. 33: $2373-82$.

Sandiumenge A, Rello J. 2012. Ventilatorassociated pneumonia caused by ESKAPE organisms: cause, clinical features, and management. Curr Opin Pulm Med. May; 18(3): 187-93.

SangeetaJoshi,

VikasGautam, VikasManchanda, JyotiBalaji et al.,2013.MRSA in India: Prevalence \& susceptibility pattern.Indian J Med Res.137.363-369.

Sathish, J.V. and Mita D. Wadekar. 2017. Prevalence of MRSA in Clinical Samples and their Antibiotic Sensitivity Pattern. Int. J. Curr. Microbiol. App. Sci. 6(7): 2338-2343.

Shah L, MullaS, Rewadiwala S.2012.Prevalence of Enterococci with higher resistnce level in a tertiary care hospital: a matter of concern.National $\mathbf{J}$ Med Res 2:25-27.

Sirijan Santajit and Nitaya Indrawattana. 2016. Mechanisms of Antimicrobial Resistance in ESKAPE Pathogens. BioMed Research International Volume 2016, Article ID 2475067, 8 pages http://dx.doi.org/10.1155/2016/2475067 
Sood S, Malhotra M, Das BK, Kapil A. 2008. Enterococal infection and antimicrobial resistance. Indian J Med Res. 128: 11121.

Suganthavalli, M, S.S.M. Umamageswari and M. Kalyani. 2017. Bacteriological profile and antimicrobial susceptibility pattern of eskape pathogens in blood culture isolated from a tertiary care centre. Int J Pharma Bio Sci. 8(4): (B) 65-69

Taneja N, Rani P, Emmanuel R, Sharma M. 2004. Significance of vancomycin resistant enterococci from urinary specimens at a tertiary care centre in northern India. Indian J Med Res., 119:72-74.

Thiago Lisboa, Fabino Nagel. 2011. Infection with multi-resistant agents in the ICU: how to escape? Rev Bras Ter Intensiva; 23(2); 120-124.
Tiwari HK, Sen MR.2006.Emergence of vancomycin resistant Staphylococcus aureus (VRSA) from a tertiary care hospital from northern part of India. BMC Infect Dis 6: 156.

Vila, J., S.Mart', and J.S'anchez-C'espedes. 2007. "Porins, efflux pumps and multidrug resistance in Acinetobacter baumannii," Journal of Antimicrobial Chemotherapy, vol. 59, no. 6, pp. 12101215.

Yong, D., M. A. Toleman, C. G. Giske et al., 2009. "Characterization of a new metallo- $\beta$-lactamase gene, bla NDM- 1 , and a novel erythromycin esterase gene carried on a unique genetic structure in Klebsiella pneumoniae sequence type 14 from India, " Antimicrobial Agents and Chemotherapy, vol. 53, no. 12, pp. 5046-5054.

\section{How to cite this article:}

Jagadevi, B. Saipriya, D.S. Shubha, K.S. Sudhindra, A. Sumantha and Madhuri, K.R. 2018. Clinical Importance of Emerging ESKAPE Pathogens and Antimicrobial Susceptibility Profile from a Tertiary Care Centre. Int.J.Curr.Microbiol.App.Sci. 7(05): 2881-2891. doi: https://doi.org/10.20546/ijcmas.2018.705.336 